\title{
Guia de Acessibilidade de Campinas: Relato de experiênCIA REALIZADA NO PROGRAMA GERAL DE EXTENSÃO DA PUC-CAMPINAS
}

\section{Accessibility Guide of Campinas: report of an experience done at a General Extension Program of PUC-Campinas}

\author{
Beatriz Helena Bueno Brandão* \\ Camila de Araújo*t \\ Juliana Caroni Medlij ${ }^{\text {th+ }}$ \\ Priscila Lina Rodrigues de Matos ${ }^{*+*+x}$
}

\begin{abstract}
RESUMO
Este relato descreve, a partir do Programa Geral de Extensão da PUC-Campinas, a experiência de realização de um Guia de Acessibilidade para a cidade, em atendimento a todos os usuários e em especial às pessoas com deficiência ou com mobilidade reduzida. O relato se propõe a socializar informações sobre o projeto proposto, quanto às referências utilizadas, as atividades desenvolvidas e em desenvolvimento, bem como sobre as oportunidades geradas nas realizações dessas atividades. O guia de acessibilidade tem modelo análogo em edição realizada para a cidade de São Paulo e publicada no ano de 2001, com informações sobre acessibilidade de deficientes físicos a ambientes, edificações, equipamentos e sistemas de comunicação. Como se trata de projeto em andamento, iniciado em 2007, é ainda relatada a programação das atividades para o ano de 2008 com as perspectivas de realização para 2009.
\end{abstract}

Palavras-chave: Guias; Acessibilidade; Pessoas com deficiência; Campinas; Cidade.

\section{SUMMARY}

This report describes, starting from the Extension General Program of PUC-Campinas, the experience of the accomplishment of a Accessibility Guide for the city, in attendance to all users and specially for the handicapped or with a reduced mobility deficiency. The report proposes to socialize information about the proposed project, as to the references used, the developed activities and the ones in development, as well as the opportunities created in the achievement of these activities. The accessibility guide as an analogous model in an edition made for the city of São Paulo and was published in 2001, with information on accessibility for the handicapped, constructions, equipments and communication systems. Because this is a project in process, initiated in 2007, it is still related in the programming of the activities for 2008 with the perspectives of consummation in 2009.

Keywords: Guides; accessibility; handicapped; campinas; city.

\section{RESUMEN}

Este relato describe, a partir del Programa General de Extensión de la PUC-Campinas, la experiencia de realización de un Guia de Acceso para la ciudad, en atención a todos los usuários y en especial a las personas con discapacidad o con movilidad reducida. El relato se propone socializar informaciones sobre el proyecto

\footnotetext{
Professa Me. do Centro de Ciências Exatas, Ambientais e de Tecnologias da PUC-Campinas.

E mail - biabrandao@puc-campinas.edu.br

* Aluna da Faculdade de Jornalismo da PUC-Campinas

*** Aluna da Faculdade de Arquitetura e Urbanismo da PUC-Campinas

Aluna da Faculdade de Arquitetura e Urbanismo da PUC-Campinas
} 
propuesto, sobre las referencias usadas, las actividades desenvueltas y en desenvolvimiento, bien como sobre las oportunidades creadas en las realizaciones de esas actividades. El guia de acceso tiene modelo análogo en edición realizada para la ciudad de São Paulo y publicada en el año 2001, con informaciones sobre el acceso de discapacitados a ambientes, construcciones, equipamentos y sistemas de comunicación. Como se trata de un proyecto en andamiento, iniciado en 2007, y todavia relatada la programación de las actividades para el año 2008 con las perspectivas de realización para 2009.

Palabras-Clave: Guias; acceso; personas con discapacidad; Campinas; ciudad.

A Pontifícia Universidade Católica de Campinas, de acordo com sua vocação de universidade confessional, tem como missão, entre outras, a de contribuir na edificação de uma sociedade justa e solidária, por intermédio de suas atividades de ensino, pesquisa e extensão.

As suas atividades de extensão desenvolvem-se, costumeiramente, nos programas de atendimento do Hospital e Maternidade Celso Pierro, bem como no Centro Interdisciplinar de Atenção ao Deficiente e em algumas atividades dos cursos dos seus diversos Centros.

Contudo, foi a regulamentação do Plano de Carreira Docente em 2006 que institucionalizou a Extensão na PUC-Campinas de modo a ajudá-la a cumprir seu papel social $e$ "criar um centro de referência do conhecimento sobre a realidade, as vicissitudes e as perspectivas da região metropolitana em que se localiza a universidade." (Circular PROEXT - 023/2006).

Nesse novo contexto universitário e no atendimento aos novos paradigmas sociais de promover a inclusão e estimular a cidadania é que surgiu a oportunidade de desenvolvimento de um Guia de Acessibilidade de Campinas, como projeto de extensão.

O tema da acessibilidade é tratado pela autora em algumas disciplinas, nas Faculdades de Arquitetura e Urbanismo e de Artes Visuais com Ênfase em Design nas quais leciona, estando desta maneira, inserida nas atividades de ensino. Foi tema ainda, de Pesquisa de Iniciação Científica, no período de 1997 e 2001 e orientada no intuito de aferir as condições de acessibilidade do Campus I da universidade, no qual a autora desenvolve suas atividades. Fal- tava, portanto, o tratamento do assunto como um trabalho de extensão universitária.

O projeto proposto teve como parâmetros os conceitos de acessibilidade vigentes na legislação brasileira (Decreto 5296/ 04) e na normalização pertinente (NBR 9050/ 04). Esses parâmetros prevêem o atendimento prioritário às pessoas com deficiência ou com mobilidade reduzida, que incluem entre outros, os idosos, os obesos, as gestantes e as mães com crianças de colo. O projeto enfoca também o conceito do Desenho Universal de atendimento à maior gama de variações possíveis das características antropométricas e sensoriais da população (NBR 9050/04).

Dessa forma, o Guia de Acessibilidade de Campinas tem como objetivo geral servir como meio de comunicação no atendimento à sociedade da Região Metropolitana de Campinas em geral, e em especial às pessoas com deficiência ou mobilidade reduzida, de modo a lhes proporcionar melhores condições de acesso na cidade, aos ambientes, edificações, equipamentos e sistemas de comunicação. Pretende assim melhorar as condições de vida das pessoas contribuindo no atendimento das condições humanas naturais de crescimento e envelhecimento.

A existência, porém, de legislação brasileira específica sobre o assunto não é garantia de respeito aos direitos dos cidadãos. Apesar de algumas situações de adaptações já existirem em cidades, edificações, equipamentos e sistemas de comunicação, o conhecimento desses fatos, bem como da própria legislação, pela população, é muito precário, quando não inexistente. Essa precariedade de informação 
justifica plenamente a função do guia como meio de informação e divulgação.

O Guia de Acessibilidade proposto tem como modelo o Guia São Paulo Adaptada elaborado para disponibilizar informações sobre acessibilidade na cidade de São Paulo e publicado em 2001. O guia paulistano foi desenvolvido somente em versão impressa e distribuído para órgãos públicos, instituições, entidades $e$ associações relacionadas às pessoas com deficiência sendo vendido ainda, na rede de supermercados Pão de Açúcar.

Observamos empiricamente que, poucas pessoas, mesmo entre as com deficiência conhecem o referido guia e ele também não foi atualizado ou reeditado. Nossa proposta, diante dessa observação é da necessidade de elaboração do Guia de Acessibilidade de Campinas, também em versão eletrônica, de modo a possibilitar sua atualização constante e seu acesso mais abrangente.

A partir da aprovação do projeto pelas instâncias competentes, procedeu-se à seleção de alunos de diferentes cursos da universidade de forma a envolver diferentes habilidades, como forma de melhor contribuir para a execução do trabalho proposto e possibilitar o exercício da transdisciplinaridade. E assim, selecionamos alunas da Faculdade de Arquitetura e Urbanismo e da Faculdade de Jornalismo. Se as primeiras têm uma maior familiaridade com os aspectos urbanos e edilícios, as seguintes têm a maior experiência do trabalho de coleta de informações, texto e divulgação.

O plano de trabalho individual das alunas foi elaborado de maneira a contemplar a diversidade das informações propostas para serem divulgadas no Guia de Acessibilidade. Como no Guia São Paulo Adaptada, as informações serão sobre o acesso a edificações $e$ espaços urbanos (arte e cultura, entretenimento e lazer); serviços (esporte, transporte, órgãos públicos e associações, serviços); leis e normas; além de informações de interesse geral. Assim, estamos elaborando o levantamento e coleta de dados e imagens dos espaços acessíveis na cidade, para numa etapa seguinte proceder a sua classificação e organização, visando às publicações em meio impresso e eletrônico dessas informações.

Cabe esclarecer que, de acordo com a proposta inicial de implantação do Programa de Extensão da PUC-Campinas, foram previstos três Núcleos Territoriais relacionados a regiões da cidade nos quais já se desenvolviam atividades de atendimento às comunidades ali existentes. Optamos por desenvolver nosso projeto no Núcleo Territorial da Catedral Metropolitana de Campinas pela sua localização na área central da cidade. Acreditamos que essa região concentraria uma maior quantidade de edifícios públicos e que, de acordo com a legislação federal em vigor, já teriam executado as adequações de acessibilidade necessárias. Nossa surpresa foi constatar que essa hipótese não se confirmava. Porém a escolha da área confirmava ainda sua vocação relativa à concentração de serviços e de moradia da população idosa.

A metodologia proposta consistiu, inicialmente, em leituras de fundamentação conceitual, bem como na utilização de variados relatos de experiências de pessoas com deficiência, abordados em filmes VHS e DVD. As informações oriundas desse material de fundamentação permitiram o nivelamento conceitual das alunas nas questões sobre legislação e normalização referentes à acessibilidade e necessárias à elaboração do roteiro de avaliação.

Esse roteiro consiste em uma planilha com os principais itens a serem avaliados nos espaços, de forma geral, e foi elaborado com base em roteiros semelhantes, como o utilizado na Pesquisa de Iniciação Científica de Avaliação do Campus I da PUC-Campinas e outros mais atuais como o do CREA-PR. Todos, de maneira geral, procuram atender aos capítulos e itens da NBR 9050/04 que trata da acessibilidade a edificações, mobiliário, espaços e equipamentos urbanos. 
A elaboração do roteiro de avaliação deu-se ao mesmo tempo em que se realizava a pesquisa dos edifícios de órgãos públicos existentes na região central de Campinas. Obtivemos uma carta de apresentação da Coordenadoria Geral de Projetos de Extensão que atestava a vinculação do projeto à Universidade de maneira a facilitar o acesso aos lugares selecionados. Nossa segunda surpresa foi constatar que, como os edifícios dos órgãos públicos não executaram as obras indicadas na legislação especifica sobre acessibilidade, em grande medida, isso contribuía para a postergação do aceite de nossa visita. Esse fato colaborou para o atraso na realização das etapas previstas em cronograma.

Um fato, no entanto, viria a contribuir significativamente para fortalecer e impulsionar nosso trabalho. Logo no início de nossas atividades extensionistas aconteceu o I Encontro Municipal de Informação e Defesa das Pessoas com Deficiência, organizado pelo Conselho Municipal de Atenção à Pessoa com Deficiência e com Necessidades Especiais, atual Conselho Municipal de Direitos da Pessoa com Deficiência, de Campinas. A participação nesse Encontro possibilitou o contato com a presidente do Conselho Municipal e o convite para apresentação do projeto do Guia de Acessibilidade de Campinas em uma das reuniões mensais.

A apresentação do Guia no Conselho Municipal abriu uma série de oportunidades de participação em eventos relacionados à causa da deficiência e nosso projeto é, invariavelmente, qualificado como fundamental pelas pessoas participantes. Entre esses eventos que participamos, cabe destacar o V Fórum Permanente de Acessibilidade em Curitiba, no mês de julho de 2007 e a organização da Semana de Luta pela Cidadania da Pessoa com Deficiência em Campinas, que aconteceu no mês de setembro. A participação na organização da Semana de Luta proporcionou que uma comitiva de pessoas com deficiência e familiares, assim como o nosso grupo, estivesse no $3^{\circ}$ Enduro da Autonomia realizado na cidade de Santos, litoral de São Paulo. E ainda, fizemos a apresentação do projeto do Guia, na Câmara Municipal de Campinas, como parte das palestras programadas. Nesse dia realizamos uma enquête sobre questões relacionadas ao Guia, cujo modelo e tabulação se encontram nos anexos e que apesar da pequena quantidade de devoluções foi muito significativa.

As questões formuladas na enquête foram relativas à área com menos informações sobre acessibilidade em Campinas, o conhecimento ou não das leis e normas sobre a acessibilidade, a contribuição no dia a dia de um guia como o proposto pelo projeto e finalmente, qual o melhor meio para veiculá-lo. Dentre as 22 pessoas que responderam a enquête, a área de órgãos públicos e associações foi a mais associada à falta de informações na cidade, seguida das áreas de arte, cultura e lazer. A resposta sobre o conhecimento das leis e normas de acessibilidade indicou um desconhecimento do assunto de mais da metade das pessoas. Quanto à propriedade do guia para a vida diária das pessoas a resposta positiva foi unanimidade. $\mathrm{E}$ no tocante à melhor veiculação do guia o meio impresso foi o mais apontado, seguido da internet. Essas respostas vieram a confirmar algumas hipóteses acerca do projeto do Guia de Acessibilidade, bem como a manutenção das etapas definidas.

Entre os contatos proporcionados pela participação nas reuniões do Conselho Municipal de Direitos da Pessoa com Deficiência, destacamos também o convite para integrar a Comissão Permanente de Acessibilidade - CPA, vinculada a Secretaria Municipal de Urbanismo da Prefeitura Municipal de Campinas. Além da participação efetiva nas reuniões quinzenais da CPA, será realizado um Curso de Extensão vinculado ao projeto do Guia, para formação dos servidores municipais em relação aos conceitos e as adequações necessárias à promoção da acessibilidade urbana e edilícia.

Extensão em Foco, Curitiba, n. 2, p. 161-172, jul./dez. 2008. Editora da UFPR 
Este relato não estaria completo ainda, se não mencionasse que além dos contatos $e$ atividades nas instituições campineiras, o projeto do Guia foi apresentado em diversos eventos da universidade. Podemos citar a participação no evento extensionista "A Universidade Socializando a Diversidade", com apresentação de trabalhos e comunicações, pelos professores da universidade e instituições convidadas sobre a temática da deficiência. E também a participação no I Encontro Anual de Extensão, da PUC-Campinas, com apresentação do desenvolvimento do trabalho pela autora e um pôster pelas alunas.

A vinculação do projeto do Guia ao Núcleo Territorial da Catedral Metropolitana de Campinas possibilitou o trabalho conjunto com os demais professores extensionistas integrados ao mesmo núcleo. Essa integração ultrapassou os limites da diversidade dos trabalhos individuais e permitiu a execução de trabalhos coletivos como a Exposição de Maria, que reuniu obras do acervo do Museu de Arte Sacra da Arquidiocese de Campinas, para visitação, na Catedral Metropolitana da cidade. O grupo de professores extensionistas, vinculados aos núcleos territoriais, buscam constantemente o intercâmbio de idéias e a prática conjunta de ações.

\section{REFERÊNCIAS}

ACESSIBILIDADE BRASIL. Disponível em: < http:// www.acessobrasil.org.br>. Acesso em: 10 jan. 2008.

ATIID - Acessibilidade, Tecnologia da Informação e Inclusão Digital. Disponível em: <http://hygeia.fsp.usp.br/acessibilidade >. Acesso em: 10 jan. 2008.

ASSOCIAÇÃO BRASILEIRA DE NORMAS TÉCNICAS. NBR 9050/04: Acessibilidade a edificações, mobiliário, espaços e equipamentos urbanos. ABNT: Rio de Janeiro, 2004.

BRASIL. Lei n. 10048 - 8 nov. 2000. Dá prioridade de atendimento às pessoas portadoras de deficiência física, aos idosos com idade igual ou superior a sessenta e cinco
Em relação ao projeto do Guia de Acessibilidade uma dessas ações conjugadas será a aplicação do roteiro de avaliação pelas senhoras freqüentadoras da Catedral e que participam do projeto de extensão da Universidade da $3^{\mathrm{a}}$ idade. Essa participação de pessoas idosas contempla o lema proposto no I Encontro Municipal de Informação e Defesa dos Direitos das Pessoas com Deficiência, em Campinas, que é "Nada sobre Nós sem Nós". Outra possibilidade de ação conjugada acontecerá quando da participação de alunos do Centro Interdisciplinar de Atenção ao Deficiente - CIAD da PUC-Campinas que é uma unidade de extensão, em alguns roteiros de avaliação.

Essas atividades todas aconteceram nos dois semestres de 2007 e foram apresentadas em relatório que avaliou os resultados esperados $e$ os efetivamente obtidos, para se necessário, proceder à reelaboração do cronograma para o biênio 2008/2009. Apresentamos, então, nova proposta que estende as etapas de classificação e organização dos dados coletados, publicação e divulgação do Guia de Acessibilidade nos meios impresso e eletrônico para este ano. Como parte integrante do projeto, a sistematização do processo de elaboração e execução do Guia será desenvolvida em 2009, para reprodução em outros Núcleos Territoriais de Extensão.

anos, às gestantes, às lactantes e às pessoas acompanhadas por crianças de colo, e dá outras providências. Brasília/ DF: Subchefia para Assuntos Jurídicos da Casa Civil, 2000.

BRASIL. Lei n. 10098 - 19 dez. 2000. Estabelece normas gerais e critérios básicos para a promoção da acessibilidade das pessoas portadoras de deficiência ou com mobilidade reduzida, e dá outras providências. Brasília/ DF: Subchefia para Assuntos Jurídicos da Casa Civil, 2000.

BRASIL. Decreto 5296 - 2 dez. 2004. Regulamenta as Leis n. 10048, de 8 de novembro de 2000, que dá prioridade de atendimento às pessoas que especifica, e 10098, de 19 de dezembro de 2000, que estabelece normas gerais e critérios básicos para a promoção da acessibilidade 
das pessoas portadoras de deficiência ou com mobilidade reduzida, e dá outras providências. Brasília/DF: Subchefia para assuntos Jurídicos da Casa Civil, 2004.

CENTER FOR UNIVERSAL DESIGN - Carolina do Norte. Disponível em: <www.design.ncsu.edu/cud/> . Acesso em: 10 jan. 2008.

CORDE- Coordenadoria Nacional para Integração da Pessoa Portadora de Deficiência. Disponível em: <http:// www.mj.gov.br/sedh/ct/corde/dpdh/corde/principal.asp>. Acesso em: 10 jan. 2008.

REDE SACI - Solidariedade, Apoio, Comunicação e Informação. Disponível em: <http://www.saci.org.br>. Acesso em: 10 jan. 2008.
SÃO PAULO. Guia de Acessibilidade em Edificações. São Paulo/SP: Comissão Permanente de Acessibilidade da Secretaria da Habitação e Desenvolvimento Urbano da Prefeitura, 2002.

SÃO PAULO. Guia de Mobilidade Urbana. São Paulo/SP: Comissão Permanente de acessibilidade da Secretaria da Habitação e Desenvolvimento Urbano da Prefeitura, 2002.

SCHWARZ, Andréa e HABER, Jaques Marcos. Guia São Paulo Adaptada. 2001. São Paulo: O Nome da Rosa, 2001.

SERPRO - Serviço Federal de Processamento de Dados Brasil. Disponível em: <http://www.serpro.gov.br/acessibilidade >. Acesso em: 10 jan. 2008.

\section{ANEXOS}

Roteiro de Avaliação - Guia de Acessibilidade de Campinas

Local:

\begin{tabular}{|l|l|l|}
\hline \multirow{4}{*}{ EXTERIOR } & Guia Rebaixada & \\
\cline { 2 - 3 } Aproximação + Sinalização & Piso regular e antiderrapante & \\
\cline { 2 - 3 } & Piso tátil ou linha guia & \\
\cline { 2 - 3 } & Placas & \\
\cline { 2 - 3 } & Símbolo internacional de acesso & \\
\cline { 2 - 3 } & $\begin{array}{l}\text { Calçadas em frente à edificação } \\
\text { em bom estado. }\end{array}$ & \\
& $\begin{array}{l}\text { - Material } \\
\text { - Dimensões }\end{array}$ & \\
\hline
\end{tabular}

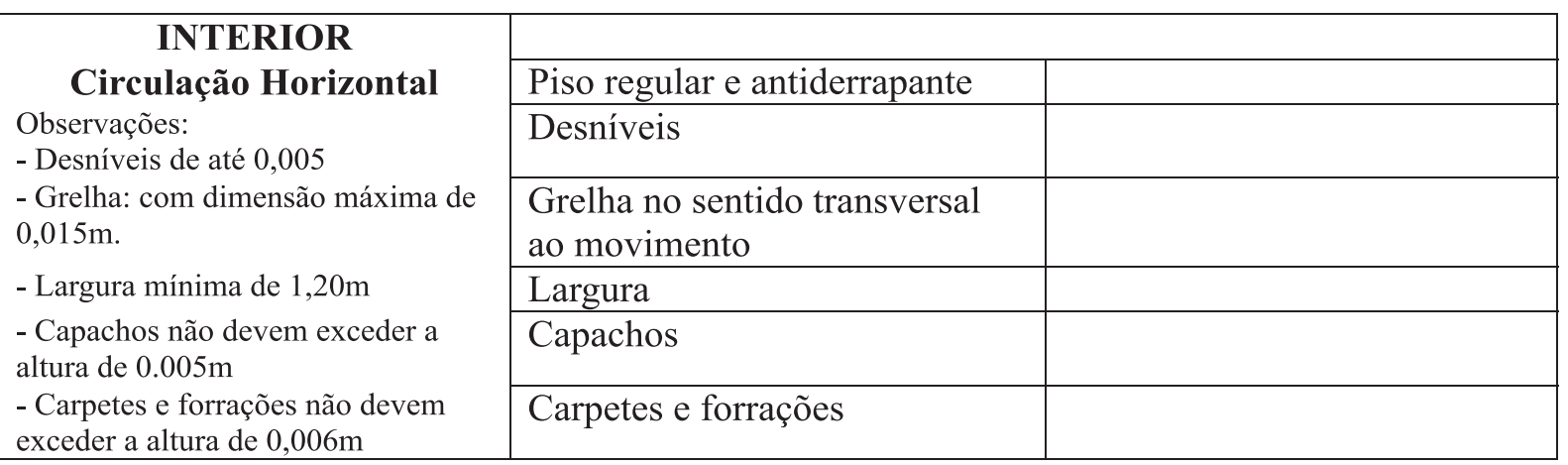




\section{Circulação Vertical - Rampas}

Observações:

- Largura mínima de 1,20m (recomendado: 1,50m)

- Guarda-corpo com altura de 1,05m do piso (quando não houver paredes adjacentes)

- Rampas em curva (inclinação máxima de 8,33\% e raio mínimo de $3 \mathrm{~m}$ )

- Patamares no início e término das rampas: largura e comprimento com mínimo de $1,20 \mathrm{~m}$ de altura

- Guia de balizamento com altura mínima de $0,05 \mathrm{~m}$

- Corrimão: - material rígido

- duas alturas: $0,7 \mathrm{~m}$ e $0,92 \mathrm{~m}$ do piso

- largura: seção circular de 0,03 a $0,045 \mathrm{~m}$

- prolongamento mínimo de $0,30 \mathrm{~m}$, antes do primeiro e após o último degrau

\begin{tabular}{|l|l|}
\hline Sinalização & \\
\hline Adequação do material & \\
\hline Desenvolvimento & \\
\hline Inclinação & \\
\hline Largura & \\
\hline Comprimento & \\
\hline Altura do guarda-corpo & \\
\hline Rampas em curva & \\
\hline $\begin{array}{l}\text { Patamares no início e término } \\
\text { das rampas: }\end{array}$ & \\
\hline Piso tátil & \\
\hline Guia de balizamento & \\
\hline Corrimão - duas alturas & \\
\hline Obstrução & \\
\hline
\end{tabular}

\begin{tabular}{|c|c|}
\hline Circulação Vertical - Escadas & Sinalização \\
\hline & Adequação do material \\
\hline Observações: & Largura \\
\hline - Largura livre mínima de $1,20 \mathrm{~m}$ & Espelhos \\
\hline - Espelhos entre 0,16 e $0,18 \mathrm{~m}$ & Pisos \\
\hline - Pisos entre 0,28 e $0,32 \mathrm{~m}$ & Patamares \\
\hline - Patamares a cada $3,20 \mathrm{~m}$ & Guarda-corpo \\
\hline $\begin{array}{l}\text { - Guarda-corpo com altura de } 1,05 \mathrm{~m} \text { do piso } \\
\text { (quando não houver paredes adjacentes) }\end{array}$ & Faixa de textura \\
\hline $\begin{array}{l}\text { - Faixa de textura diferenciada, no início e } \\
\text { término da escada (mínimo de } 0.28 \mathrm{~m} \text { ) }\end{array}$ & Corrimão com duas alturas \\
\hline $\begin{array}{l}\text { - Corrimão: - material rígido } \\
\text { - deve haver duas alturas: } 0,7 \mathrm{~m} \text { e } 0,92 \mathrm{~m} \text { do } \\
\text { piso } \\
\text { - largura: seção circular de } 0,03 \text { a } 0,045 \mathrm{~m} \\
\text { - prolongamento mínimo de } 0,30 \mathrm{~m} \text {, antes do } \\
\text { primeiro e após o último degrau }\end{array}$ & Obstrução \\
\hline
\end{tabular}

\section{Circulação Vertical - Elevadores}

Observações:

- Cabina com dimensões mínimas de $1,10 \mathrm{x}$

$1,40 \mathrm{~m}$

- Espelho na face posta

- Identificação em Braille do pavimento no

batente com altura entre 0,90 e $1,10 \mathrm{~m}$

- Botoeiras localizadas entre 0,89 e $1,30 \mathrm{~m}$

- Braille localizado no lado esquerdo do botão

\begin{tabular}{|l|l|}
$\begin{array}{l}\text { Sinalização tátil e visual } \\
\text { nos pisos e paredes }\end{array}$ & \\
\hline $\begin{array}{l}\text { Sinalização visual e auditiva } \\
\text { para sinalização do andar }\end{array}$ & \\
\hline Dimensões da cabine & \\
\hline Espelho & \\
\hline Identificação em Braille & \\
\hline Botoeiras & \\
\hline
\end{tabular}




\section{Circulação Vertical Plataformas móveis}

Observações:

- Desníveis máximo de $0,015 \mathrm{~m}$

\begin{tabular}{|l|l|}
\hline Sinalização - visual e tátil & \\
\hline Alarme sonoro e luminoso & \\
\hline Desníveis \\
\hline Projeção sinalizada no piso & \\
\hline $\begin{array}{l}\text { Barras de proteção e } \\
\text { guarda-corpo }\end{array}$ & \\
\hline
\end{tabular}

\begin{tabular}{|c|c|}
\hline \multirow[b]{2}{*}{$\begin{array}{l}\text { Circulação interna - Corredores } \\
\text { Observaçoes: } \\
\text { - Largura: } \\
\text { - } 0,90 \mathrm{~m} \text { (Os elevadores com até } 4 \mathrm{~m} \text { de } \\
\text { extensão) } \\
\text { - } 1,20 \mathrm{~m} \text { para corredores com até } 10 \mathrm{~m} \text { de } \\
\text { extensão } \\
\text { - } 1,50 \mathrm{~m} \text { para corredores com extensão } \\
\text { superior a } 10 \mathrm{~m} \\
\text { - } 1,50 \mathrm{~m} \text { para corredores de uso público } \\
\text { - Para corredores longos deve haver um bolsão a } \\
\text { cada } 15 \mathrm{~m} \text { para manobrar a cadeira de rodas. }\end{array}$} & Largura \\
\hline & Comprimento \\
\hline
\end{tabular}

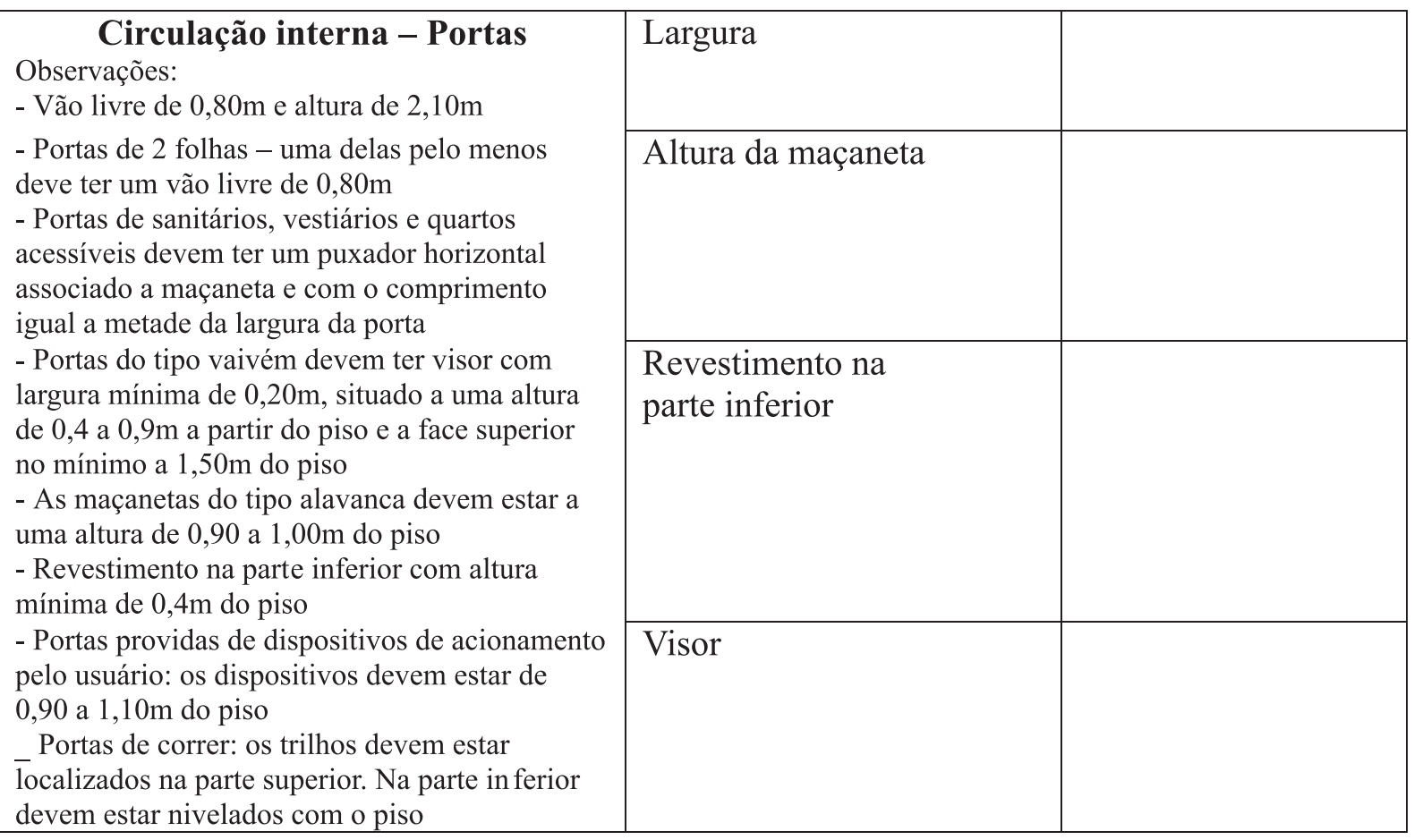




\begin{tabular}{|l|l|l|}
\hline \multicolumn{1}{|c|}{ Circulação Interna - Janelas } & Altura & \\
\cline { 2 - 3 } $\begin{array}{l}\text { Observaços: } \\
\text { Altura das janelas devem ser de } 1,00 \text { a } 1,35 \mathrm{~m} \\
\text { Trinco ou maçaneta do tipo alavanca }\end{array}$ & Altura da maçaneta & \\
\hline
\end{tabular}

\begin{tabular}{|l|l|l|}
\hline \multirow{4}{*}{ Sanitários Convencionais } & Sinalização & \\
\cline { 2 - 3 } & Visor & \\
\hline & Proteção inferior na porta & \\
\hline & Altura da maçaneta & \\
\hline & Dimensão da porta & \\
\hline & Dimensão & \\
\hline & Altura do vaso sanitário & \\
\hline & Lavatório & \\
\hline & Torneiras & \\
\hline & Mictório - altura do piso & \\
\hline & $\begin{array}{l}\text { Mictório - altura da } \\
\text { descarga }\end{array}$ & \\
\hline
\end{tabular}

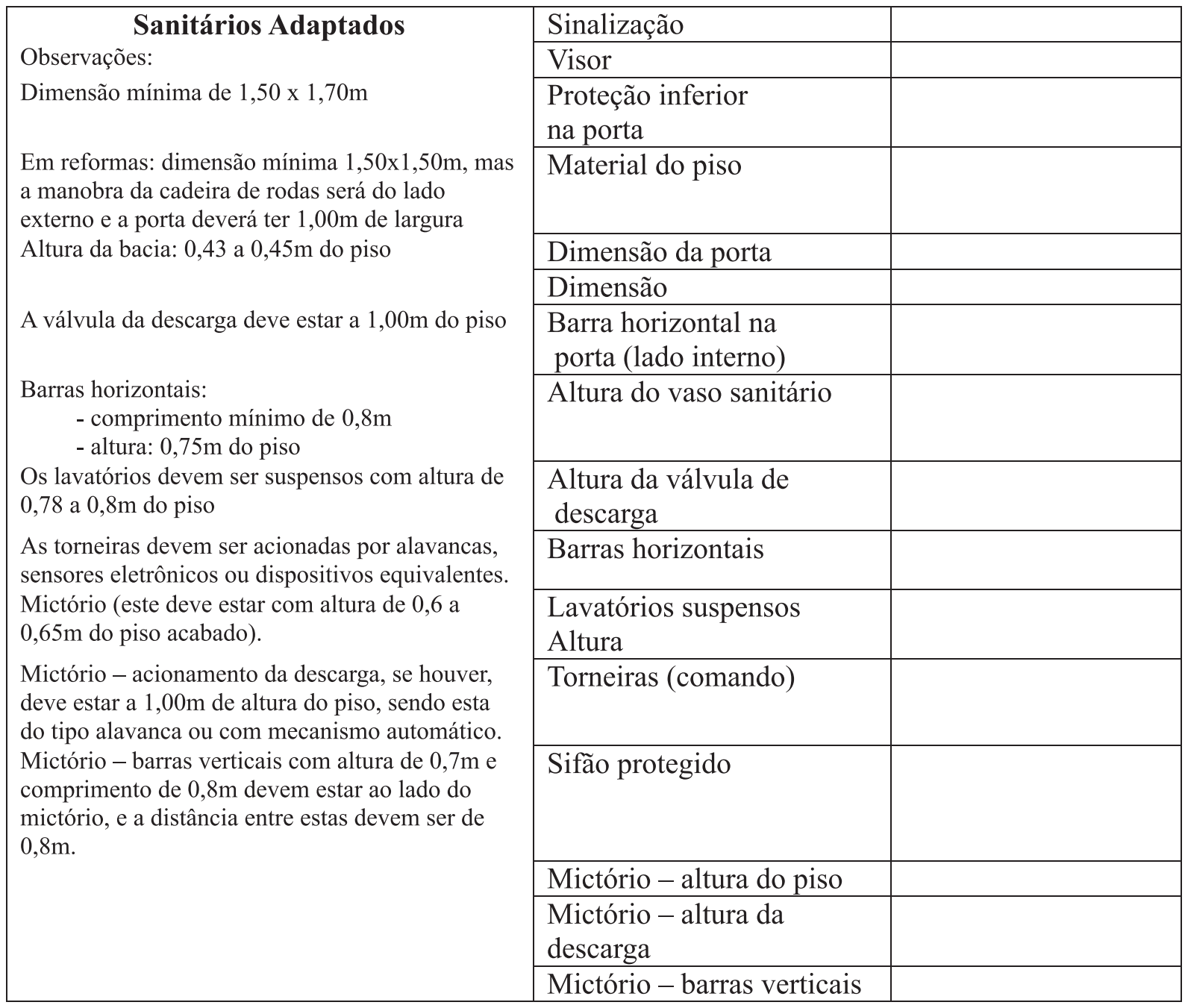




\begin{tabular}{|c|c|}
\hline Mobiliário Interno - Bebedouro & Altura \\
\hline Observações: & $\begin{array}{l}\text { Área de aproximação } \\
\text { frontal }\end{array}$ \\
\hline $\begin{array}{l}\text { - Altura: } 0,9 \mathrm{~m} \\
\text { - Área de aproximação frontal, possibilitando } \\
\text { avançar sob o bebedouro até no máximo } 0,5 \mathrm{~m}\end{array}$ & Altura livre inferior \\
\hline $\begin{array}{l}\text { - Altura livre inferior: no mínimo } 0,73 \mathrm{~m} \text { do piso } \\
\text { - Copos descartáveis devem estar localizados a } \\
\text { uma altura de no máximo } 1,20 \mathrm{~m}\end{array}$ & Copos descartáveis \\
\hline
\end{tabular}

\begin{tabular}{|l|l|l|}
\hline Mobiliário Interno - Mesas ou & Altura livre inferior & \\
superfícies para refeitórios ou & & \\
trabalho & & \\
Observações: & & \\
- $5 \%$ devem ser acessíveis & \\
- Aproximação frontal, possibilitando avançar & & \\
sob as mesas ou superfícies até no máximo $0,5 \mathrm{~m}$ & & \\
- Altura livre inferior: no mínimo $0,73 \mathrm{~m}$ do piso & & \\
- Deve haver uma faixa livre de circulação de & & \\
$0,9 \mathrm{~m}$ & & \\
- Altura deve estar entre 0,75 a $0,85 \mathrm{~m}$ do piso & & \\
\hline
\end{tabular}

\begin{tabular}{|l|l|l|}
\hline Mobiliário Interno - Balcão de & Altura livre inferior & \\
Atendimento & & \\
$\begin{array}{l}\text { Observações: } \\
\text { - Altura de no máximo } 0,9 \mathrm{~m} \text { do piso } \\
\text { - Altura livre inferior a } 0,93 \mathrm{~m} \text { do piso } \\
\text { - Profundidade: no mínimo } 0,3 \mathrm{~m}\end{array}$ & Profundidade & \\
\hline
\end{tabular}

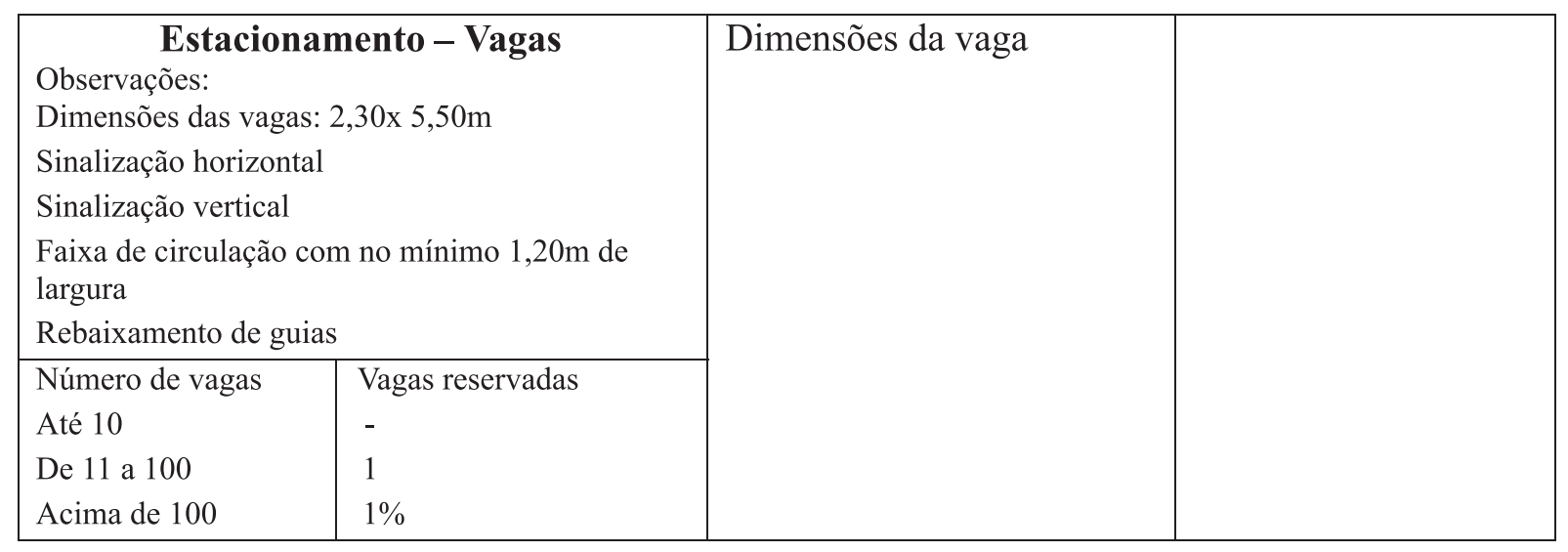




\section{ENQUÊTE}

1- Qual é a área que falta mais informações sobre a acessibilidade em Campinas?
a) arte, cultura e lazer
b) esporte
c) órgãos públicos e associações
d) outros:

2- Você conhece as leis e normas sobre a acessibilidade?
a) $\operatorname{sim}$
b) não

3- Um guia com o objetivo de melhorar as informações sobre acesso na cidade, aos ambientes, edificações, equipamentos e sistemas de comunicação para pessoas com deficiência ou mobilidade reduzida contribuiria no seu dia a dia?
a) $\operatorname{sim}$
b) não

4- Se sim, qual o melhor meio a ser veiculado?
a) internet
b) impresso
c) outros:

\section{TABULAÇÃO DA ENQUETE}

22 pessoas responderam a enquête.

1 - Qual é a área que falta mais informações sobre a acessibilidade em Campinas? (21 respostas tabuladas)
a) arte,cultura e lazer $\mathbf{3 8 , 0 9 \%}$
b) esporte $\mathbf{4 , 7 8 \%}$
c) órgãos públicos e associações $\mathbf{4 2 , 8 5 \%}$
d) outros $14,28 \%$
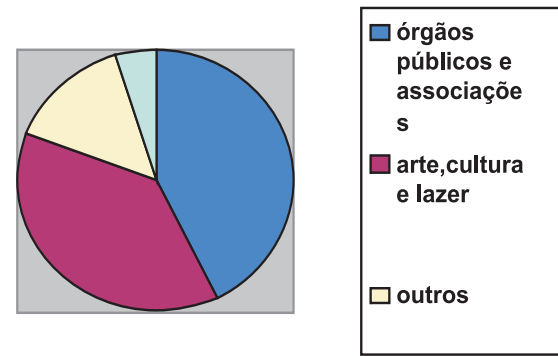

OBS.: As pessoas que responderam outros alegaram que não moram em Campinas (3 casos). Houve também um caso em que a pessoa marcou as alternativas $\mathrm{a}, \mathrm{b}$ e c. Esse último caso não está tabulado.

Sugeriram também informação sobre empresas.

2 - Você conhece as leis e normas sobre a acessibilidade? (22 respostas tabuladas)
a) $\mathrm{Sim}$
$\mathbf{4 2 , 8 6 \%}$
b) Não
$57,14 \%$

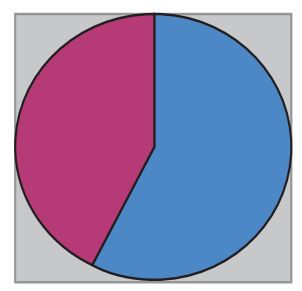

$$
\begin{array}{|l}
\square \text { não } \\
\square \operatorname{sim}
\end{array}
$$

OBS.: Houve um caso que disse estar tomando conhecimento no dia do evento. 
3 - Um guia com o objetivo de melhorar as informações sobre o acesso na cidade, aos ambientes, edificações, equipamentos e sistemas de comunicação para pessoas com deficiência ou mobilidade reduzida contribuiria no seu dia a dia? (22 respostas tabuladas)
a) $\quad \operatorname{Sim} \mathbf{1 0 0 \%}$
b) Não $\mathbf{0 \%}$

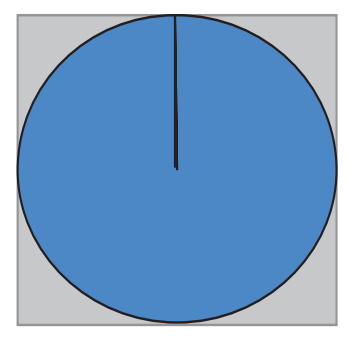

4 - Se sim, qual o melhor meio a ser veiculado? (20 respostas tabuladas)
a) Internet $\mathbf{3 5 \%}$
b) Impresso $\mathbf{6 0 \%}$
c) Outros $\quad \mathbf{5 \%}$

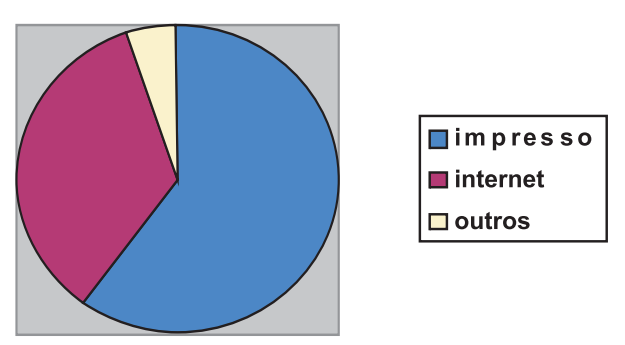

OBS: Houve dois casos em que a pessoa assinalou as opções a e b, esses não foram tabulados.

Sugestões de veicular na TV, murais e jornais e em site de fácil acesso e com muita divulgação.

Texto recebido em 21 fev. 2008. Texto aprovado em 25 mar. 2008. 